\title{
Educadores de Criança: Condições de Trabalho e Vida
}

Children Educators: Job And Life Conditions

Educadores De Niños: Condiciones De Trabajo Y Vida
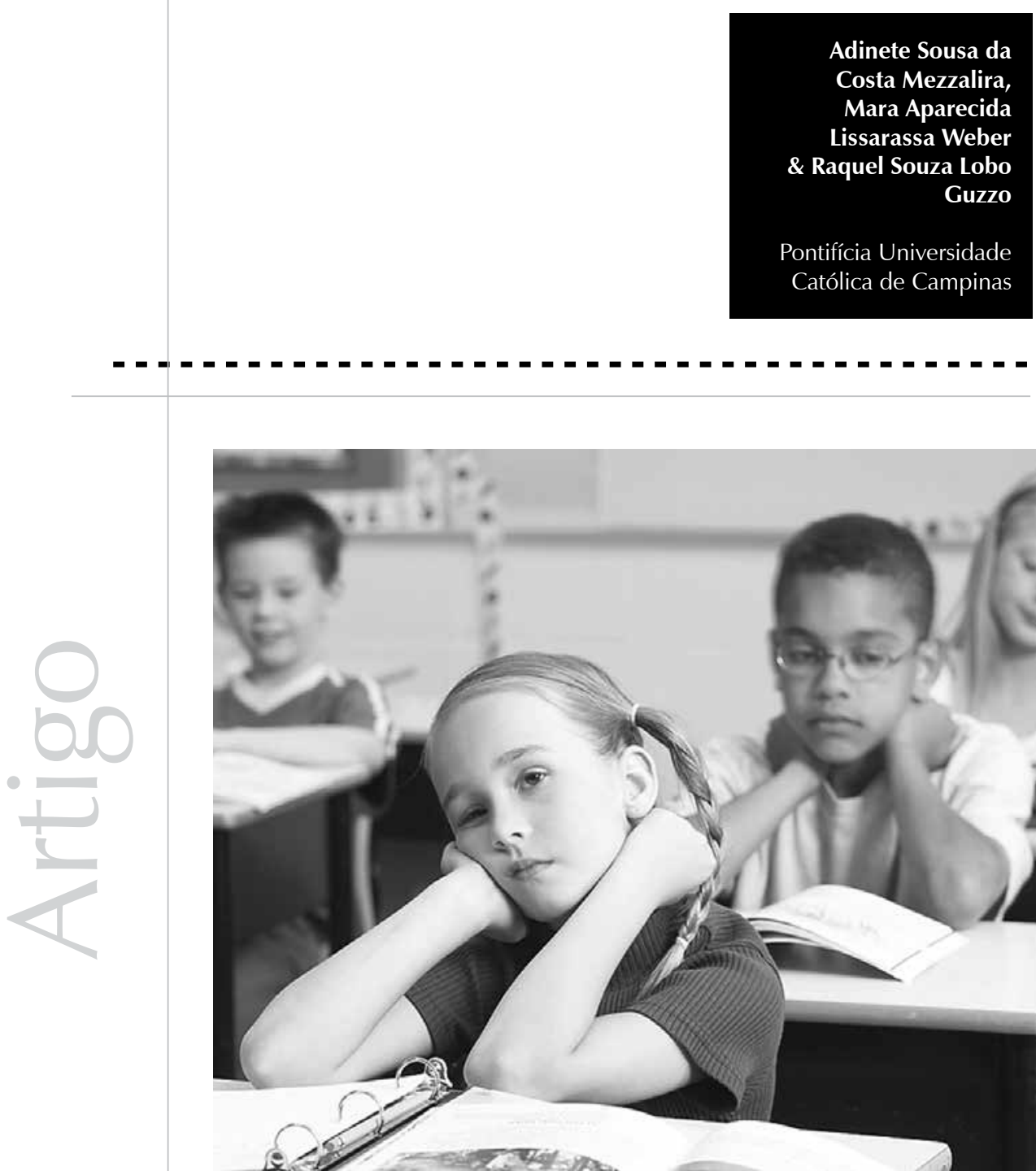
Resumo: A alienação, o fatalismo e a conscientização no espaço escolar são abordados neste estudo, que teve o objetivo de investigar como trabalhadoras da educação de uma escola pública de educação infantil percebiam as dimensões de seu trabalho nesse contexto. A pesquisa utilizou a abordagem qualitativa, e os dados foram obtidos por meio da análise de 35 questionários preenchidos por professores, monitores e pela equipe gestora de uma escola municipal de educação infantil. Os resultados revelaram que as trabalhadoras, em sua maioria, vivenciam situações de opressão nas relações de poder existentes na escola, o que as tem impedido de, nesse contexto, desenvolver-se como indivíduos construtores de sua própria história e, portanto, como transformadores de sua realidade. Diante disso, entendemos ser fundamental uma ação consciente do psicólogo escolar, intervindo nas relações de poder existentes na escola com o objetivo de assegurar o desenvolvimento pleno e saudável das crianças e dos trabalhadores da educação.

Palavras-chave: Educação infantil. Pessoal da educação. Atuação do psicólogo. Conscientização. Psicologia escolar.

Abstract: Alienation, fatalism and consciousness in school are considered in this study, which aimed
to investigate how educators from a public kindergarten perceived the dimensions of their work in this
context. The research used a qualitative approach and the data were obtained through the analysis of 35
questionnaires completed by school teachers, group leaders and the management team. The results showed
that the workers, mostly, had experienced oppression in the existing school power relations. This experience
had prevented them from developing as individuals in this context, constructing their own history and
therefore being able to transform reality. Due to this, we understand how important a conscious action of
the school psychologist intervening in the existing power relations in school is, in order to ensure the whole
and healthy development of children and educational workers. Keywords: Child education. Educational personnel. Psychologist performance. Awareness. School psychology.

Resumen: La alienación, el fatalismo y la concientización en el espacio escolar son abordados en este estudio, el cual tuvo el objetivo de investigar como trabajadoras de la educación de una escuela pública de educación infantil percibían las dimensiones de su trabajo en ese contexto. El estudio utilizó el abordaje cualitativo y los datos fueron obtenidos por medio del análisis de 35 cuestionarios llenados por profesores, monitores y el equipo gestor de una escuela municipal de educación infantil. Los resultados apuntaron que las trabajadoras, en su mayoría, vivencian situaciones de opresión en las relaciones de poder existentes en la escuela, lo que las ha impedido de, en ese contexto, desarrollarse como individuos constructores de su propia historia y, por lo tanto, transformadores de su realidad. Ante esto, entendemos como fundamental una acción consciente del psicólogo escolar interviniendo en las relaciones de poder existentes en la escuela con el objetivo de asegurar el desarrollo pleno y saludable de los niños y de los trabajadores de la Educación. Palabras clave: Educación infantil. Personal de la educación. Actuation del psicólogo escolar. Concientización. Psicología escolar.

A temática do trabalho tem sido alvo de interesse de pesquisadores por constituir atividade fundamental para o processo de desenvolvimento do indivíduo, pois, segundo Martín-Baró (2000), por meio do trabalho, o homem organiza a sua vida pessoal e as suas relações humanas. Assim, neste artigo, para entendermos como o trabalho tem impactado na vida das profissionais de uma instituição municipal de educação infantil, partiremos do conceito de trabalho, definido por Marx como:

... um processo de que participam o homem e a natureza, processo em que o ser humano com sua própria ação impulsiona, regula e controla seu intercâmbio material com a natureza. Defronta-se com a natureza como uma de suas forças. Põe em movimento as forças naturais de seu corpo, braços e pernas, cabeça e mãos, a fim de apropriar-se dos recursos da natureza, imprimindo-lhes forma útil à vida humana. Atuando assim sobre a natureza externa e modificando-a, ao mesmo tempo modifica sua própria natureza (2011, p.211)

A partir dessa definição, Bertoldo (2011) aponta que, na busca de satisfazer as suas necessidades básicas para sobreviver, o homem se apropria da natureza transformando-a segundo seus desejos e necessidades. Essa satisfação acontece por meio do trabalho, caracterizado como uma atividade vital consciente, a partir do qual o homem é capaz de estabelecer um objetivo e buscar meios na 


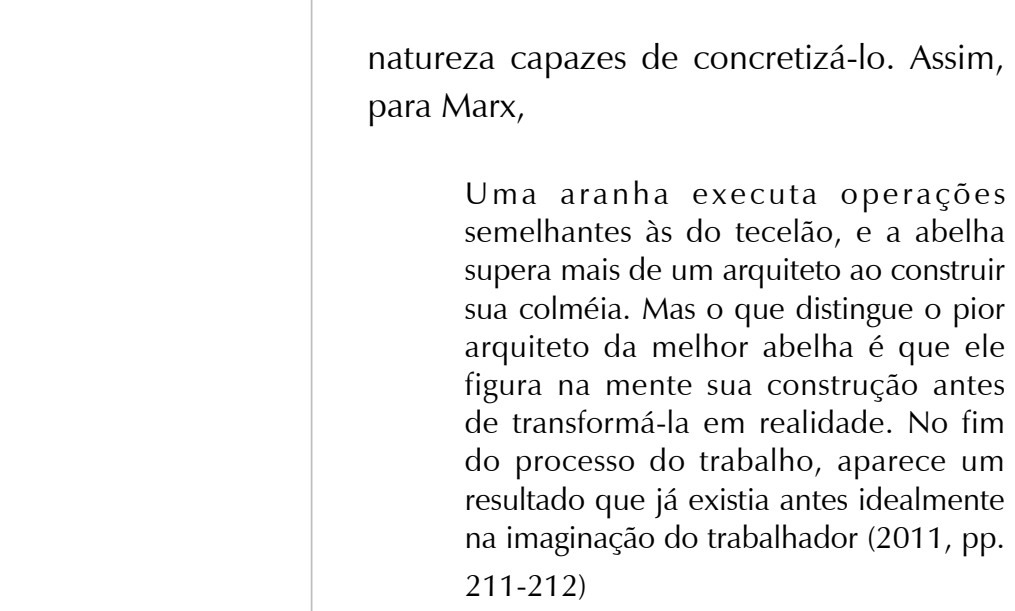

Uma aranha executa operações semelhantes às do tecelão, e a abelha supera mais de um arquiteto ao construir sua colméia. Mas o que distingue o pior arquiteto da melhor abelha é que ele figura na mente sua construção antes de transformá-la em realidade. No fim do processo do trabalho, aparece um resultado que já existia antes idealmente na imaginação do trabalhador (2011, pp. 211 212) natureza capazes de concretizá-lo. Assim,

Uma aranha executa operações semelhantes às do tecelão, e a abelha supera mais de um arquiteto ao construir sua colméia. Mas o que distingue o pior arquiteto da melhor abelha é que ele do processo do trabalho, aparece um resultado que já existia antes idealmente 211-212)

Com base nas ideias de Marx, Lessa e Tonet (2008) e Bertoldo (2011) afirmam que, ao agir sobre a natureza - ação mediada pelo trabalho -, o homem, primeiramente, idealiza a sua ação para depois concretizá-la, e, assim, torna-se consciente de sua atividade. Durante esse processo de concretização de suas ideias, o homem vai adquirindo novos conhecimentos e habilidades, tornando-se produto e produtor da realidade, pois, ao mesmo tempo em que transforma a natureza, também é transformado.

Esse processo de objetivação - concretização das ideias -, no entanto, pode transformar-se em obstáculo para o desenvolvimento quando o indivíduo acredita em uma ideia que não pode ser concretizada. Para Lessa e Tonet, quando os seres humanos realizam "préviasideações que não levam em consideração o que a realidade de fato é, tendem a conduzir a objetivações malsucedidas" (2008, p. 102). Os autores explicam que, por vivermos em uma sociedade capitalista, são impulsionadas, cotidianamente, ideias cujo objetivo é o de iludir o indivíduo para manter a estrutura social de dominação e subordinação. Os autores afirmam ainda que, a partir do momento em que o indivíduo acredita nessas prévias-ideações irrealizáveis, terá o seu processo de desenvolvimento impedido e estará inserido em um processo alienante. Conforme argumenta Freire (1980, 1996), não existe outra maneira de superar o cotidiano alienante senão por meio da práxis histórica - ação e reflexão. Essa práxis se dá por meio da conscientização, definida pelo autor como um processo de tomada de consciência que ultrapassa a esfera espontânea de apreensão da realidade e que exige do homem uma penetração na essência fenomênica do objeto. Dessa forma, é possível ter uma posição epistemológica capaz de superar a postura do conhecimento do objeto e de agir para transformá-lo.

O papel dos profissionais da educação nesse processo de conscientização, segundo Lessa e Tonet, é o de contribuir para que ele aconteça, ao considerar que se trata de um trabalho que, no capitalismo, está voltado não para a transformação da natureza, mas para a mediação da ideologia, trabalhando diretamente nas relações sociais:

a práxis do assistente social e a do professor são muito semelhantes. Ambos operam sobre as pessoas e as relações sociais e não transformam diretamente a natureza. Por isso, para os dois profissionais, a ideologia é uma mediação fundamental: tanto para o professor quanto para o assistente social; trata-se de modificar o que as pessoas pensam, como elas sentem, como elas percebem o mundo em que vivem, para que seja possível a alteração (ou a manutenção) de determinadas relações sociais (2008, p. 2)

Diante desse argumento, acreditamos que a profissão do psicólogo também se configure como uma práxis que está voltada para a mediação da ideologia. Pesquisas como as de Patto (1984) e de Yamamoto (1987), por exemplo, atestam que, durante a sua história, a Psicologia operou, ideologicamente, para manter as relações de poder por meio de ações e de pressupostos teóricos que justificavam as diferenças individuais e que ignoravam as dimensões políticas.

A ideologia, como função mediadora das relações sociais, tem na literatura um amplo 
debate. Dobles (1999) a define como um processo social que tem como propósito ocultar as contradições sociais e legitimar o poder e as injustiças sociais. Lane (1999), por sua vez, expõe que, nas sociedades capitalistas e em favor de uma minoria, a ideologia tem como objetivo introduzir conceitos históricos e, muitas vezes, distorcidos como se fossem naturais. A autora cita, como exemplo, a espúria ideia de que a sociedade é construída a partir das relações de autoridade e de inferioridade, que introjeta no indivíduo a concepção de que a relação opressor $x$ oprimido é algo inerente à sociedade e, portanto, não tem como ser mudada.

Na visão de Freire (1996) a naturalização do fenômeno social - crença de que os fatos ou acontecimentos não podem ser mudados - tem implicações diretas no comportamento dos indivíduos. Para esse autor, ao acreditar que a sua condição de exclusão seja impossível de ser alterada, o indivíduo adota uma postura fatalista diante do contexto em que vive, e, portanto, sentese convencido de que nada pode fazer para mudar a sua realidade social. Assim, de histórica e cultural, essa realidade passa a ser vista como um fenômeno natural e imutável.

Nessa mesma perspectiva, encontra-se Martín-Baró, que realizou um estudo aprofundado sobre o que seria o fatalismo, definindo-o como:

... compreensão da existência humana, segundo a qual o destino de todos é pré-determinado e todo fato acontece de forma inevitável. Os seres humanos não têm escolhas a não ser cumprir o seu destino, a sorte passa a prescrever o seu destino" (1998, p. 76)

Para esse pesquisador, quando um indivíduo assume uma atitude fatalista, torna-se conformista e passivo frente às circunstâncias da vida, acreditando que nada pode fazer para modificar a sua situação a não ser adaptar- se à sua realidade. Diante dessa análise, fica claro que a adoção de uma postura fatalista é devastadora para o desenvolvimento pleno do indivíduo. Como argumenta Freire (1987), o fatalismo impede o impulso de transformação e de busca, condições essas necessárias para que o homem se torne sujeito da própria história.

Diante desse importante obstáculo ao desenvolvimento humano, Martín-Baró (1996) propõe a desideologização como tarefa do psicólogo, com vistas a promover a autonomia e a libertação de indivíduos e grupos. O psicólogo precisa estar atento a quem tem o poder nas relações sociais, pois são os grupos dominantes que ditam as regras, as normas e as leis, a fim de preservar a acomodação do homem diante da sua situação de opressão.

Ao se pensar, em especial, em uma intervenção do psicólogo escolar voltada para a autonomia e a libertação dos indivíduos, a sua ação perpassa, necessariamente, pelo trabalho em conjunto com os educadores na construção de um projeto político-pedagógico emancipador. Dentro dessa proposta, Sant'Ana, em sua pesquisa de doutorado, enfatizou a importância de o psicólogo escolar promover atividades dirigidas para a conscientização e o fortalecimento do corpo docente a fim de se efetivar um projeto político-pedagógico pautado em uma orientação emancipatória da educação. Essa intervenção do psicólogo exige a identificação de processos psicossociais como a alienação e fatalismo, porque:

a alienação certamente é um processo que faz com o que o educador não adote a perspectiva emancipadora em sua prática profissional. Na medida em que o educador não tem consciência e uma postura crítica diante das desigualdades sociais, e não se engaja na sua superação, continua reproduzindo as relações de dominação presentes no sistema capitalista (2008, p. 213) 
1 Nesta pesquisa, utilizamos a expressão trabalhadoras da educação por dois motivos: primeiramente, para designar os

diferentes trabalhadores da escola, tais como diretora, orientadora pedagógica, educadora especial, professora e monitoras; segundo, porque nós nos

baseamos em uma abordagem marxistaontológica, que coloca

a categoria trabalho como o cerne para elucidar a gênese e o desenvolvimento do ser social. Para uma leitura geral sobre a utilização do termo trabalhador da educação, sugerimos, entre outras, as seguintes pesquisas: A Educação na Sociedade de Classes: Possibilidades e Limites, de Paulino Orso, e De Trabalhador a Profissional da Educação: o Fim da Luta de Classe? de Edna Bertoldo.

2 Projeto de extensão financiado pelo CNPq e coordenado pela profa - Dr- Raquel Souza Lobo Guzzo. Essa proposta de intervenção traz contribuições para a formação em nível de graduação e pós-graduação na área da Psicologia escolar e educacional, pois possibilita interligar os três segmentos-base: ensino, pesquisa e extensão.

3 A formação continuada é uma atividade que acontece na escola a cada dois meses, no período da manhã, e que conta com a participação de todos os trabalhadores da escola: diretora, vice-diretora, orientadora pedagógica, educadora especial, professoras, monitoras, cozinheiras e auxiliares de limpeza. Nos dias em que essas atividades ocorrem, as crianças não vão à escola.
É importante pontuar que, nesse contexto e ao assumir esse tipo de intervenção emancipadora, o psicólogo não se torna o único profissional responsável pela libertação dos indivíduos no contexto escolar. Segundo Freire, ninguém liberta ninguém, a libertação dos homens ocorre em comunhão. Ao discutirem essa perspectiva, Penteado e Guzzo (2010) afirmam que, como nenhuma ciência é desprendida da realidade, tanto a educação como a Psicologia produzem conhecimentos e práticas que podem ser utilizados como instrumentos de dominação, e, assim, tornam-se ciências que servem à ideologia dominante. Observa-se, portanto, que romper a ideologia dominante torna-se uma necessidade urgente para combater os fenômenos psicossociais - como alienação e fatalismo - que têm interferido na formação dos diversos profissionais que atuam como indivíduos livres e autônomos dentro de uma escola.

Diante do exposto, este estudo tem como objetivo investigar como as trabalhadoras da educação ${ }^{1}$ de uma instituição municipal de educação infantil têm percebido o seu trabalho nesse contexto ideológico de alienação e fatalismo.

\section{Método}

Essa investigação adota a proposta de pesquisa apresentada por Parker (1995, 2004, 2005), que sustenta que toda investigação é uma ação que trabalha a favor ou contra o poder. O autor considera a pesquisa qualitativa como uma das investigações que apresenta um viés metodológico capaz de desconstruir as ideias naturalizadas acerca dos fenômenos sociais. Com isso, a partir dos relatos do participante, busca entender como as condições sociais o influenciam a fazer determinadas afirmações e a comportar-se de determinada maneira.

Nessa perspectiva, o método qualitativo de análise dos dados torna-se importante para este estudo por tornar possível a análise dos relatos, a fim de se conhecer as situações de poder, resistência, opressão e fatalismo, que se encontram imbuídas na estrutura social da escola.

\section{Cenário da pesquisa}

O local de realização da pesquisa foi um Centro Integrado Municipal de Educação Infantil - CIMEI, localizado em uma grande cidade do interior do Estado de São Paulo. O centro atende, aproximadamente, 400 crianças, com idade entre três meses a seis anos, entre os turnos da manhã e da tarde. O quadro de funcionários da escola é composto por diretora, vice-diretora, orientadoras pedagógicas, educadoras especiais, professoras, monitoras, cozinheiras, auxiliares de limpeza e seguranças.

\section{Procedimento da pesquisa}

A pesquisa foi realizada em uma instituição de educação infantil no âmbito de um projeto de extensão denominado Voo da Águia ${ }^{2}$, cuja finalidade precípua é a promoção e o acompanhamento do desenvolvimento emocional e social de crianças a partir da discussão com famílias e professor sobre os processos educativos em diferentes contextos e situações do cotidiano.

Ao participarmos de uma das atividades desenvolvidas na escola, denominada Formação Continuada - $\mathrm{FC}^{3}$, a orientadora pedagógica expôs a necessidade de caracterizar todos os trabalhadores da escola, isto é, diretora, vice-diretora, coordenadora pedagógica, educadoras especiais, professoras, monitoras, cozinheiras e serventes, com o objetivo de colocar essa caracterização no projeto pedagógico da instituição. A equipe de Psicologia do projeto Voo da Águia, diante dessa demanda da escola, colocou-se à disposição para 
fazer esse levantamento e participar dessa discussão. Foi elaborado um questionário que continha três partes. Na primeira, foram obtidos dados de identificação pessoal; na segunda, foram inseridas informações sobre a profissão por meio das seguintes questões: cargo que exerce na escola, tempo de serviço na escola, formação escolar e experiência profissional; por último, na terceira parte, foi indagado sobre a forma como gostaria de ser reconhecida na escola.

O procedimento de entrega desses questionários ocorreu da seguinte forma: a escola colocou o questionário no caderno de ponto de maneira que diretora, orientadora pedagógica, professoras, educadoras especiais, monitoras, serventes e cozinheiras pudessem pegá-lo, respondêlo e, posteriormente, entregá-lo à equipe da Psicologia. A realização dessa atividade por esses trabalhadores da escola não era obrigatória.

\section{Resultados e discussão}

As respostas fornecidas pelas educadoras ao questionário foram organizadas pelas sínteses feitas às três partes estruturais do instrumento: (a) identificação pessoal, (b) identificação do trabalho e (c) forma como gostariam de ser reconhecidas na escola.

\section{Identificação das participantes}

4 Compo sto por diretora, vicediretora, orientadoras pedagógicas, educadoras especiais, professoras, monitoras, cozinheiras, auxiliares de limpeza e seguranças.

5 Diretora, vicediretora e orientadora pedagógica. tinham entre 32 e 43 anos; nove, entre 44 e 53 anos; sete, entre 54 e 67 anos.

No que diz respeito à quantidade de filhos, $88,5 \%$ possuíam filhos, e $11,5 \%$, não. No grupo das educadoras com filhos, $40 \%$ possuíam dois filhos, $28,5 \%$ possuíam um filho e $17 \%$ possuíam três ou quatro filhos. Apenas uma monitora possuía sete filhos. Com esse resultado, percebe-se que $85,5 \%$ das participantes não possuem uma família grande, tendo, em média, três filhos.

\section{Identificação do trabalho das participantes}

Neste tópico, buscou-se conhecer três aspectos: o tempo de trabalho na escola, a formação escolar e o trabalho desenvolvido na instituição. A respeito do tempo de trabalho na escola, 65\% estão nessa instituição há no máximo dez anos, e 35\% trabalham com educação escolar há mais de dez anos.

Com relação à escolaridade das participantes, $63 \%$ possuem ensino superior. Essa formação concentra-se, prioritariamente, nos cargos de professora, educadora especial e da equipe gestora $^{5}$, pois apenas uma monitora tem o ensino superior. A formação das monitoras concentra-se no ensino fundamental I ou II (38\%) e no ensino médio (54\%).

A despeito do trabalho desenvolvido na instituição, obtivemos respostas a partir das quais as participantes relataram que a sua profissão tem se configurado como um processo de aprendizagem. Isso se aproxima claramente das constatações de Freire (1987), ao afirmar que, por meio da relação dialógica na educação, o indivíduo impulsiona o seu processo de desenvolvimento como sujeito capaz de modificar a realidade e, ao mesmo tempo, de ser modificado. Observe-se o trecho a seguir: 
A cada ano, enfrento novas dificuldades e desafios, mas sempre carrego um fundinho de frustração por não realizar um trabalho com a qualidade que eu gostaria, por falta de estrutura e por estarmos numa engrenagem de um sistema maior, muitas vezes, inacessivel. (professora 15)
Uma profissão gratificante, onde estou sempre aprendendo coisas novas. Vejo como uma profissão dinâmica e enriquecedora. (professora 06)

Esse processo de adquirir novos conhecimentos, de aprender a partir da experiência só ocorre, segundo Freire, quando o educador assume a postura de não apenas transmitir os seus conhecimentos mas também de aprender por meio das relações construídas com os outros indivíduos no ambiente escolar.

Ao contrário disso, se o indivíduo não reconhece o trabalho como uma manifestação da própria vida, a sua atividade torna-se apenas um meio de subsistência, levando-o ao esgotamento físico e emocional (Mészáros, 2006), isso porque, quando o indivíduo não se transforma por meio do seu trabalho, essa sua atividade não se torna parte da sua história, e, por conseguinte, ele não vivencia o processo de transformar e de ser transformado. No trecho a seguir, uma professora exemplifica essa situação ao responder que o seu trabalho na escola é apenas:

Se dar, dar, dar e não esperar nada em troca. (professora 12)

O trabalho dessa professora tem se tornado um obstáculo para o seu desenvolvimento humano, conduzindo-a a um processo alienado e alienante, considerando-se que a alienação é o estranhamento que o indivíduo possui em relação ao seu trabalho, sem encontrar sentido para a atividade desempenhada (Mészáros, 2006). Da mesma forma, esse estranhamento também é apontado na seguinte observação:

- Já tive muito prazer em fazer tudo que minha profissão exige. Hoje, perdi a 'alegria pedagógica'. (professora 09)
A pesquisadora Carlotto (2003) já explicava que, nas atividades docentes, encontram-se presentes diversos estressores psicossociais, que pode estar relacionados à natureza de suas funções ou ao contexto institucional e social onde são exercidas. Esses estressores, se persistentes, podem afetar o ambiente educacional e interferir na obtenção dos objetivos pedagógicos, levando os educadores a um processo de alienação, desumanização e apatia, como também pode ser visto a seguir:

A cada ano, enfrento novas dificuldades e desafios, mas sempre carrego um fundinho de frustração por não realizar um trabalho com a qualidade que eu gostaria, por falta de estrutura e por estarmos numa engrenagem de um sistema maior, muitas vezes, inacessível. (professora 15)

Essa professora reconhece os seus limites diante do sistema maior, e a consciência dessa limitação, de acordo com Konder (2000), impulsiona o indivíduo a pensar em como poderia ultrapassar o obstáculo apresentado. A superação, porém, dessa limitação não ocorre apenas no plano ideal, mas a partir do movimento concreto dos seres humanos. A necessidade da práxis - ação e reflexão - no processo de conscientização foi bastante discutida por Freire (1980). Para esse pesquisador, a conscientização implica, necessariamente, a inserção do homem na História como sujeito que cria e recria o mundo. A conscientização não é, portanto, apenas uma tomada de consciência do homem sobre determinada situação. Há, pois, a obrigatoriedade de uma posição dialética entre o pensar e o fazer.

A atenção a essa dialética e a compreensão de como ela concretamente se verifica na ação do homem perante o mundo fornecem subsídios importantes para entendermos o comportamento fatalista. Ao conhecer a realidade à luz de uma ideologia capitalista, o homem acredita que nada pode ser feito 
para mudar a situação concreta em razão de o mundo e de as relações sociais serem naturalmente constituídas dessa forma. $\mathrm{O}$ homem, então, apropria-se de uma falsa consciência do mundo, que irá dificultar tanto o seu desenvolvimento como o dos outros ao seu redor, sobretudo no caso de educadores e crianças. Como no trecho citado anteriormente pela professora 15, há uma consciência de se fazer parte da "engrenagem de um sistema maior", mas ela acredita que essa engrenagem seja imutável, e, portanto, conforme a sua resposta, "inacessível". Essa resposta pode parecer fatalista à medida que a professora se percebe como impotente diante da realidade e se utiliza de argumentos ideologizados que naturalizam o fenômeno social.

\section{Como as trabalhadoras gostariam de ser reconhecidas na escola}

Essa categoria permitiu uma reflexão de como as relações têm se constituído na escola a partir da análise das respostas das trabalhadoras à questão aberta "Como você gostaria de ser reconhecido na escola?" Com base nos resultados obtidos, pudemos fazer algumas reflexões.

As educadoras, responderam que gostariam de ser vistas como profissionais que devem ser respeitadas e reconhecidas por sua competência na atuação, pois são responsáveis, dedicadas e buscam atualizarse:

- Como uma profissional qualificada para desempenhar sua função e que gosta do que faz. (professora 14)

- Costaria de ser reconhecida pelos meus serviços prestados ao longo dos anos com muita dedicação. (monitora 35)

A busca por esse reconhecimento é admitida como de fundamental importância para Martín-Baró (2000) ao considerar que, no trabalho, o homem encontra o verdadeiro sentido da sua vida, pois, ao ter consciência da importância de sua atividade para a sociedade, irá reconhecer-se como alguém que traz algo valioso para os outros. Ao adquirir uma perspectiva sobre si mesmo e sobre os outros, consegue identificar os direitos e os deveres sociais sobre o mundo. Segundo o autor, quando se sente como uma parte insignificante e substituível desse processo, o indíviduo perde o significado e o sentido do trabalho, e este se torna uma fonte de alienação, de estranhamento e de desintegração pessoal.

Romper esse desmerecimento ao trabalho do educador é uma necessidade urgente. $\mathrm{O}$ trabalhador deve sentir-se parte integrante do trabalho, e não um indivíduo descartável e sem valor para a escola. Um outro agravante percebido na resposta das participantes foi a necessidade de serem ouvidas e respeitadas em suas opiniões:

\section{- Costaria de ser reconhecida como uma profissional que quando leva algum fato até a direção, que seja ouvida e respeitada em sua opinião. (monitora 31) \\ - Fazendo parte da equipe escolar, tendo espaço para dar opiniões em relação de qualquer assunto da minha ossada, com respeito humano e respeito profissional. (monitora 34) \\ - Gostaria de ser reconhecida como profissional. Sinto que muitas vezes são ditas coisas e acontecem mudanças sem ao menos me comunicarem. (professora 19)}

Essa ausência de participação dessas trabalhadoras nas decisões da escola compromete de modo significativo o seu desenvolvimento. Conforme explica Freire (1987), quando não é incluído em uma situação e se sente incapaz de transformar e de ser transformado, o homem não se percebe como sujeito da História, e, assim, abre-se perspectiva para uma postura fatalista. De acordo com o autor, a exclusão do homem 
na tomada de decisão torna-o alienado de suas decisões, colocando no outro a decisão das suas escolhas, o que se configura como uma situação de violência. Qualquer que seja a situação em que alguns homens proíbam aos outros que sejam sujeitos de sua busca, fica instaurada uma situação de abuso de poder e de exploração de um homem sobre outro homem.

A importância de uma decisão ser coletivizada foi discutida por Konder ao observar que as mudanças históricas mais profundas e significativas ocorreram sempre por participações coletivas. O autor explica, no entanto, que essa ação coletiva tem sido prejudicada em nossa sociedade em virtude da divisão social do trabalho, em que as pessoas estão reunidas, mas desunidas. Em acréscimo a essa problemática, nas escolas públicas, existe uma grande rotatividade de profissionais, que, segundo Dias-da-Silva e Fernandes (2008), impede a concretização de um trabalho coletivo. Torna-se algo inviável o desenvolvimento de atividades coletivizadas em uma equipe itinerante e rotativa, composta por professores, coordenadores, diretores e supervisores.

Além das dificuldades encontradas para reunir a equipe escolar, há outro agravante: os professores/escola são impedidos de exercerem a sua autonomia. Como bem explicam Dias-da-Silva e Fernandes, a autonomia oferecida às escolas é ilusória, pois "o controle apresenta-se atualmente de forma mais sutil, dominante e desagregador" (2008, p. 8). A construção e a aplicação das políticas públicas educacionais acontecem sem a participação dos educadores. Por mais que apresentem argumentos com base em suas experiências, as quais, muitas vezes, justificam um posicionamento contrário ao tomado pelas instâncias de poder, esses profissionais são obrigados a cumprir as ordens estabelecidas nas escolas. E o descumprimento dessas ordens políticas acarreta prejuízos concretos à carreira.

Carlotto (2003) explica, também, que essa exclusão do professor nas decisões institucionais, em que é concebido como um executor de propostas e de ideias gestadas por outros, tem desmotivado esse profissional a desenvolver suas tarefas e levado-o a não se perceber como um profissional respeitado. Por isso, encontramos respostas das participantes declarando que gostariam de ser vistas pela escola com respeito:

- Com respeito, compromisso, seriedade. Possuo embasamento teórico e prática pedagógica, considerando-me uma educadora. (professora 17)

- Como parte integrante da equipe escolar. Como professora de educação especial, e reconhecida e respeitada como tal. (professora 02)

- Como um ser humano que sou, ser respeitada dentro dos direitos e como profissional. (monitora 32)

Há relatos que demonstram o interesse das educadoras em contribuir com o trabalho pedagógico com ações e discussões, desenvolvendo ações planejadas e visando à melhoria do processo educativo e à efetivação das ações propostas. Essas educadoras possuem uma visão de atividade coletiva em que cada um colabora para a construção de um trabalho eficaz:

- Como educadora que faz parte da equipe, que tenta contribuir no trabalho pedagógico com ações e nas discussões, que como qualquer um tem acertos e erros, mas sem medo de tentar. (equipe gestora 01)

- Pela proposta de trabalho que pretendo realizar. Ideias novas, o real comprometimento com a educação das crianças, de forma inovadora, teorizada, estudando junto com o grupo e construindo um projeto realmente efetivo. (equipe gestora 03)

- Como um profissional que acredita no 
desenvolvimento de um trabalho planejado que contemple as vivências e experiências do time que compõe este CIMEl, visando à excelência do processo educativo e à efetivação das ações propostas. (equipe gestora 05)

Nos relatos dessas trabalhadoras que participam ativamente dos processos decisórios da escola, encontramos manifestações de comprometimento e de envolvimento com o trabalho pedagógico, pois planejam atividades sempre no âmbito coletivo. A busca por soluções de problemas, no entanto, nem sempre ocorria na esfera coletiva, e podemos encontrar exemplos de educadoras que tentavam resolver os problemas sociais a partir de ações individuais, tal como explicitado neste relato:

- Como alguém que deseja ver um mundo com menos diferenças sociais e que vem, principalmente, com o desejo de dar um pouquinho do que falta a essas crianças: amor, carinho, atenção, compreensão. (professora 11)

Sant'Ana (2008), em seu estudo, ressaltou, entre outros aspectos, que uma das alternativas possíveis para enfrentar o processo de adoecimento dos educadores reside na necessidade da conscientização das condições que alienam o ser humano, além da necessidade de uma organização política na luta por melhores condições de trabalho e de vida.

\section{Considerações finais}

Os resultados encontrados revelaram que as trabalhadoras da educação, em sua grande maioria, mostraram-se frustradas, desmotivadas e desrespeitadas com e no seu trabalho. Essa condição pode indicar que elas se encontram em situação de vulnerabilidade por vivenciarem, dentro do espaço escolar, ações que as impedem de desenvolver-se como indivíduos construtores de sua própria história e, portanto, como transformadores de sua realidade.

Outro aspecto importante encontrado nos resultados refere-se à necessidade de possibilitar a esse trabalhador que tome parte nas decisões que ocorrem nas atividades do seu cotidiano de trabalho. Como bem explica Freire, quando as pessoas são incluídas nos processos decisórios, percebem-se como um ser que capaz de modificar a realidade ao seu redor e romper a postura fatalista. A presente pesquisa revela essa perspectiva de Freire quando constata que as integrantes da equipe gestora, por se sentirem partícipes das tomadas de decisões, conseguiam reconhecer a importância de sua atividade e planejá-las sempre de forma coletivizada.

Essas constatações sobre o trabalho das educadoras foram percebidas a partir de uma análise aprofundada, presente e constante no ambiente escolar, sobre as relações sociais entre os trabalhadores da educação. A partir da perspectiva teórico-filosófica adotada nesta pesquisa, conseguimos entender e analisar as relações de poder e as situações complexas existentes no dia a dia escolar. É diante dessa complexidade que encontramos na pesquisa de Costa (2010) informações que nos fazem refletir sobre a importância de o psicólogo escolar aprofundar o seu olhar nas questões das relações de poder existentes na dinâmica escolar, pois, sem esse cuidado, podemos tanto correr o risco de assumir uma postura preconceituosa a respeito do educador quanto traçar estratégias de intervenção descontextualizadas e ineficazes.

Dessa maneira, torna-se relevante incluir, nas ações do psicólogo escolar, a construção de espaços capazes de propiciar aos educadores um momento de reflexão sobre a importância da participação de todos os envolvidos nos processos decisórios da escola. Tal fato poderia garantir mudanças quanto à percepção de que os trabalhadores escolares são sujeitos capazes de modificar a sua 
realidade, assim como teria reflexos nas atividades desenvolvidas com os alunos dentro da instituição escolar.

Por fim, não podemos deixar de enfatizar que a luta pela transformação das relações de poder existentes na educação ultrapassa as ações realizadas no espaço escolar. Como bem explica Orso (2008), a educação se transforma de acordo com o movimento da sociedade, e o fato de vivermos em uma sociedade de classes nos obriga a considerar que a educação tem servido para a manutenção dessa estrutura social, e mudá-la exige, portanto, uma transformação social. O trabalhador da educação - nessa categoria incluímos também o psicólogo escolar - precisa reconhecer que a sua ação revolucionária deve transpor o interior da escola e atingir as bases da estrutura social, que tem inibido e bloqueado qualquer ação que possa promover uma educação diferente. Lutar por uma educação emacipadora impõe, necessariamente, o combate a todas as relações sociais de poder existentes na sociedade capitalista.

\section{Adinete Sousa da Costa Mezzalira}

Doutora em Psicologia como Profissão e Ciência pela Pontifícia Universidade Católica de Campinas, Campinas - SP - Brasil.

E-mail: adinetecosta@hotmail.com

\section{Mara Aparecida Lissarassa Weber}

Doutora em Psicologia como Profissão e Ciência pela Pontifícia Universidade Católica de Campinas, Campinas -SP-Brasil.

E-mail: maraweber09@yahoo.com.br

\section{Raquel Souza Lobo Guzzo}

Doutora em Psicologia e docente da Pontifícia Universidade Católica de Campinas, Campinas - SP - Brasil.

E-mail: rguzzo@mpc.com.br

Endereço para envio de correspondência:

Rua Santa Monica, 136, casa 1. CEP: 13100-101. Campinas, SP.

Recebido 05/06/2012, 1a Reformulação 23/02/2013, Aprovado 11/04/2013. 


\section{Referências}

Bertoldo, E. (2011). De trabalhador a profissional da educação: o fim da luta de classe? In V Encontro Brasileiro de Educação e Marxismo. Marxismo, Educação e Emancipação Humana. Universidade Federal de Santa Catarina. Florianópolis, SC.

Carlotto, M. S. (2003). Burnout e o trabalho docente: considerações sobre a intervenção. InterAção Psy, 1(1),12-18.

Costa, A. S. (2010). Desenvolvimento da criança na educação infantil: uma proposta de acompanhamento. (Tese de Doutorado). Pontifícia Universidade Católica de Campinas, SP.

Dias-da-Silva, M. H. G. F., \& Fernandes, M. J. S. (2006, nov.). As condições de trabalho dos professores e o trabalho coletivo: mais uma armadilha das reformas educacionais neoliberais? In VI Seminário da REDESTRADO - Regulação Educacional e Trabalho Docente. UERJ - Rio de Janeiro, RJ.

Dobles, I. (1999). Marxism, ideology and psychology. Theory \& Psychology, 9(3), 407-410.

Freire, P. (1980). Conscientização: teoria e prática da libertação (3a ed.). São Paulo: Moraes.

Freire, P. (1987). Pedagogia do oprimido (17a ed.). Rio de Janeiro: Paz e Terra.

Freire, P. (1996). Pedagogia da autonomia: saberes necessários à prática educativa (29a ed.). São Paulo: Paz e Terra.

Konder, L. (2000). Os sofrimentos do homem burguês. São Paulo: Editora SENAC.

Lessa, S., \& Tonet, I. (2008). Introdução à filosofia de Marx. São Paulo: Expressão Popular.

Lane, S. T. M. (1999). Ideology and consciousness. Theory \& Psychology, 9(3), 367- 378.

Martín-Baró, I. (1996). O papel do psicólogo. Estudos de Psicologia, 2(1), 7-27.

Martín-Baró, I. (1998). El latino indolente. In A. Blanco (Ed.), Psicología de la liberación (pp. 73-101). Madrid: Trotta.

Martín - Baró, I. (2000). La interacción personal contexto y percepción. In I. Martín-Baró. Acción y ideología: psicología social desde Centroamérica (pp. 183-239). San Salvador: UCA Editores.

Marx, K. (2011). Processo de trabalho e processo de produzir mais-valia. In K. Marx O capital (29a ed., pp. 209-231). Rio de Janeiro: Civilização Brasileira.

Mészáros, I. (2006). A teoria da alienação em Marx. São Paulo: Boitempo.

Orso, P. J. (2008). A educação na sociedade de classes: possibilidades e limites. In P. J. Orso, S. R. Gonçalves \& V. M. Mattos (Orgs.), Educação e luta de classes. São Paulo: Expressão Popular.

Parker, I. (1995). Qualitative research. Psychology Review, 2(2), 13-15.

Parker, I. (2004). A desconstrução da psicopatologia na pesquisa ação. Mental, 2(3), 15-29.

Parker, I. (2005). Qualitative psychology: Introducing radical research. NY: Open University Express - McGRaw, Hill Education.

Patto, M. H. S. (1984). Psicologia e ideologia: uma introdução crítica à psicologia escolar. São Paulo: T. A. Queiroz.

Penteado, T. C. Z., \& Guzzo, R. S. L. (2010). Educação e psicologia: a construção de um projeto político-pedagógico emancipador. In F. Lacerda Jr. \& R. S. L. Guzzo. Psicologia \& sociedade: interfaces no debate sobre a questão social (pp. 257-277) Campinas, SP: Alínea.

Pires, M. F. C. (1997). O materialismo histórico-dialético e a educação. Interface: Comunicação, Saúde e Educação, 1, 83-94.

Sant'Ana, I. M. (2008). Projeto político-pedagógico, trabalho docente e emancipação: a relação psicólogo-professor em processo de construção. (Tese de Doutorado). Pontifícia Universidade Católica de Campinas, SP.

Yamamoto, O. H. (1987). A crise e as alternativas da psicologia. São Paulo: Edicon. 